\title{
Enantioselective Protonation of Enolates in Natural Product Synthesis**
}

\author{
Charles Fehr*
}

\begin{abstract}
Since their discovery in 1967 , the damascones with their typical fruity flowery scent and exceptional odor strength, have become important perfume components. Our interest originated in the synthesis of $(E)$-prop-1-enyl ketones starting from appropriate carboxylic-acid derivatives by Grignard mono-addition. In the presence of LDA, nonenolizable or slowly enolizable esters or carboxamides are converted into ketones which are protected from further reaction by their in situ conversion into enolates. The predominant formation of $(E)$-enolates is of synthetic interest, and this point is discussed in the last section. Alternatively, regioisomeric enolates of defined configuration could be obtained by first converting esters into their $\mathrm{Li}$-enolates which react with organometallic reagents to afford directly ketone- and aldehyde enolates. This sequence is applied to the synthesis of $\gamma$-damascone. Likewise, such enolates can be protonated enantioselectively (up to $84 \%$ ee) by use of a judiciously chosen chiral proton donor. This has allowed the synthesis of enantiomerically pure $(R)$ - and' $(S)$ - $\alpha$-damascone. The outcome of this reaction critically depends on the presence of lithium alkoxide ligands. Enantioselective protonation is presently being applied to a planned synthesis of $\alpha$-irisfuran, a recently isolated iris oil constituent. In the last section, a novel access to trimethyl-trans-decalins is discussed. The success of this synthetic approach critically depends on the diastereocontrolled formation of a trienolate and its corresponding silyl ether, the latter being submitted to a thermal electrocyclic reaction. This novel reactive sequence has allowed the synthesis of bicyclic damascone analogs which exhibit interesting organoleptic properties and opens a new route for the direct construction of biologically active $\mathrm{C}(6)$-functionalized drimanes such as cinnamodial and forskolin.
\end{abstract}

\section{General Synthesis of Ketones from Esters and Carboxamides by Use of Mixed Organolithium-Magnesium Reagents: Synthesis of $\alpha$-Damascone, $\beta$-Damascone, and $\beta$-Damascenone}

Some years ago, we became interested in a direct approach to the precious rose ketones $\alpha$-damascone (1), $\beta$-damascone (2), and $\beta$-damascenone (3) starting from an appropriate ester precursor. The methyl $\alpha$-and $\beta$-cyclogeranates 5 and $\mathbf{6}$ are synthetically useful, easily accessible precursors of the rose ketones 1 and 2 [1]. However, as may be expected, Grignard reaction with allylmagnesium chloride on esters 5 and 6 mainly leads to the corresponding tertiary alcohols, the products of di-addition, which result from a second nucleophilic attack of allylmagnesium chloride on the intermediate ketone and only minor amounts of the desired ketones are obtained. We reasoned that for substrate esters or amides with a low tendency to

\footnotetext{
*Correspondence: Dr. C. Fehr

Firmenich SA

Research Laboratories

P.O. Box $23, \mathrm{CH}-1211$ Geneva 8

**Based on the Ruzicka Prize Lecture,

'Enantioselektive Protonierung von Enolaten zur

Synthese von Naturstoffen', given at the ETH

Zürich, September 10, 1990.
}

enolize, the presence of a strong external base would protect the intermediate prop-2enyl ketone from further reaction by rapid deprotonation to its enolate.

Indeed, the normal Grignard reactivity could be completely reversed, when performed in the presence of LDA. Under these conditions, the regioselective deprotonation of the in situ generated ketone is faster than a second nucleophilic attack by allylmagnesium chloride, thus leading almost exclusively and in high yield to the corresponding damascones [2]. E.g. $\alpha$-damascone (1) was obtained from methyl $\alpha$-cyclogeranate (5) in $85 \%$ yield with a ketone to alcohol selectivity of 98:2 (Scheme 1). Likewise, $\beta$-damascone (2) and $\beta$-damascenone (3) were obtained with good selectivity and in high yields from esters 6 and 8 [3]. As shown in Entry 2, the resultant enolate can also be trapped with $\mathrm{Me}_{3} \mathrm{SiCl}$ giving rise to a 3: I mixture of $(E)$ - and $(Z)$-enol-silyl ethers 7. As we shall see later on, the predominant formation of the $(E)$-isomer is also of especial synthetic interest.

In general, the amides react even more selectively than the esters, but with considerably diminished reactivity [2][4]. Whereas ester 9 reacts with Grignard reagent 4 to give a 2:1 mixture of ketone $\mathbf{1 0}$ and di-addition product 11 , amide 12 reacts with increased selectivity to afford $\mathbf{1 0}$ and $\mathbf{1 1}$ in a

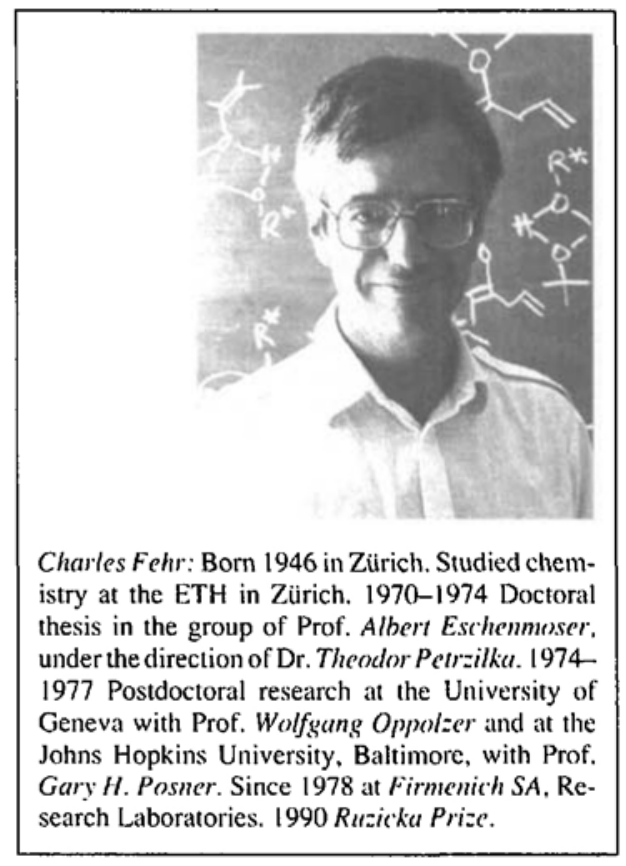

92:8 ratio. After $75 \%$ conversion, the selectivity amounts to $99: 1$. Thus, although the ease of deprotonation of the generated ketone is a prerequisite for a successful reaction, the selectivity also depends on the nature of the leaving group and on the species present in the reaction medium. The fact that the constitution of the reacting species is almost certainly modified during the reaction makes the complete understanding of the monoGrignard reaction even more difficult. We postulate that the reagent 4 , possibly present as a mixed aggregate, also undergoes complexation with the substrate ester or amide, thus imparting partial intramolecular character to the whole transformation (nucleophilic attack of allylmetal derivative, elimination of 'ROM' or ' $\mathrm{R}_{2} \mathrm{NM}$ ' and deprotonation of the ketone).

Subsequently, we have extended the application of the Grignard mono-addition to other allylic and non-allylic Grignard reagents [5]. As an illustration, hydroxy ketones 14a,b, precursors of artemisia ketone $(\mathbf{1 5})$, could be obtained from the aldolate 13 generated in situ by methallyl Grignard reaction (Scheme 2).

Reaction of Ester Enolates with Nucleophiles: Stereocontrolled Formation of Ketone and Aldehyde Enolates. Synthesis of $\gamma$-Damascone

$\gamma$ Damascone (17), in contrast to the other rose ketones discussed above, is not naturally occurring, but, nonetheless, has also very interesting odor properties. Whereas previously reported syntheses are too laborious for industrial use [6], our novel approach provides an extremely efficient access to 17 [7] (Scheme 3).

Thus, methyl $\beta$-cyclogeranate (6) was successively treated with BuLi and allylmagnesium chloride to give ketone $\mathbf{1 6}$ in $80 \%$ yield. $\gamma$ Damascone was then obtained 
in almost quantitative yield by isomerization of the terminal $\mathrm{C}=\mathrm{C}$ bond under acidic conditions. It should be noted that application of slightly modified conditions - allylmagnesium chloride/LDA - converts the same ester 6 into $\beta$-damascone (2) (Scheme 1 ). Whereas the reaction is accompanied by $10 \%$ of di-addition product, the synthesis of $\gamma$-damascone proceeds with complete selectivity, no di-addition products being detected. Under the same conditions methyl $\beta$ safranate (18) was converted into $\gamma$ damascenone (19). Closer inspection of this organometallic transformation reveals that, in a first step, the ester is deprotonated with BuLi. Indeed, trapping of 20 with $\mathrm{Me}_{3} \mathrm{SiCl}$ leads to a mixture of ketene acetal 23 and $C$ silylated ester 24 (Scheme 4). In a second step, the anionic species $\mathbf{2 0}$ reacts with allylmagnesium chloride to afford ketone enolate 21. Silylation led nearly exclusively to the $(E)$-silyl-enol ether 22, whereas ketone 16 was obtained upon aqueous workup.

How can this concept of an electrophilic ester enolate be defended? Due to the fact that the negative charge is delocalized over five centers (Scheme 5), the carbonyl group retains a part of its electrophilic character. In addition, we know that for steric reasons the carboxy group of ester 6 is twisted out of the plane of the $\pi$-system [8]. Therefore, a hypothetical allyl anion ester system may also be considered as a reactive structure. Interestingly, several cases of nucleophilic additions on carbonyl systems bearing a partial negative charge are known, e.g. the carboxylates 27 [9] and diketo enolates 28 [10] which represent vinylogous carboxylates. As shown by de Groot et al. [11], the deprotonated ester-aldehyde 29 is also able to undergo $\mathrm{C}-\mathrm{C}$ bond formation when treated with a Grignard reagent and the anionic

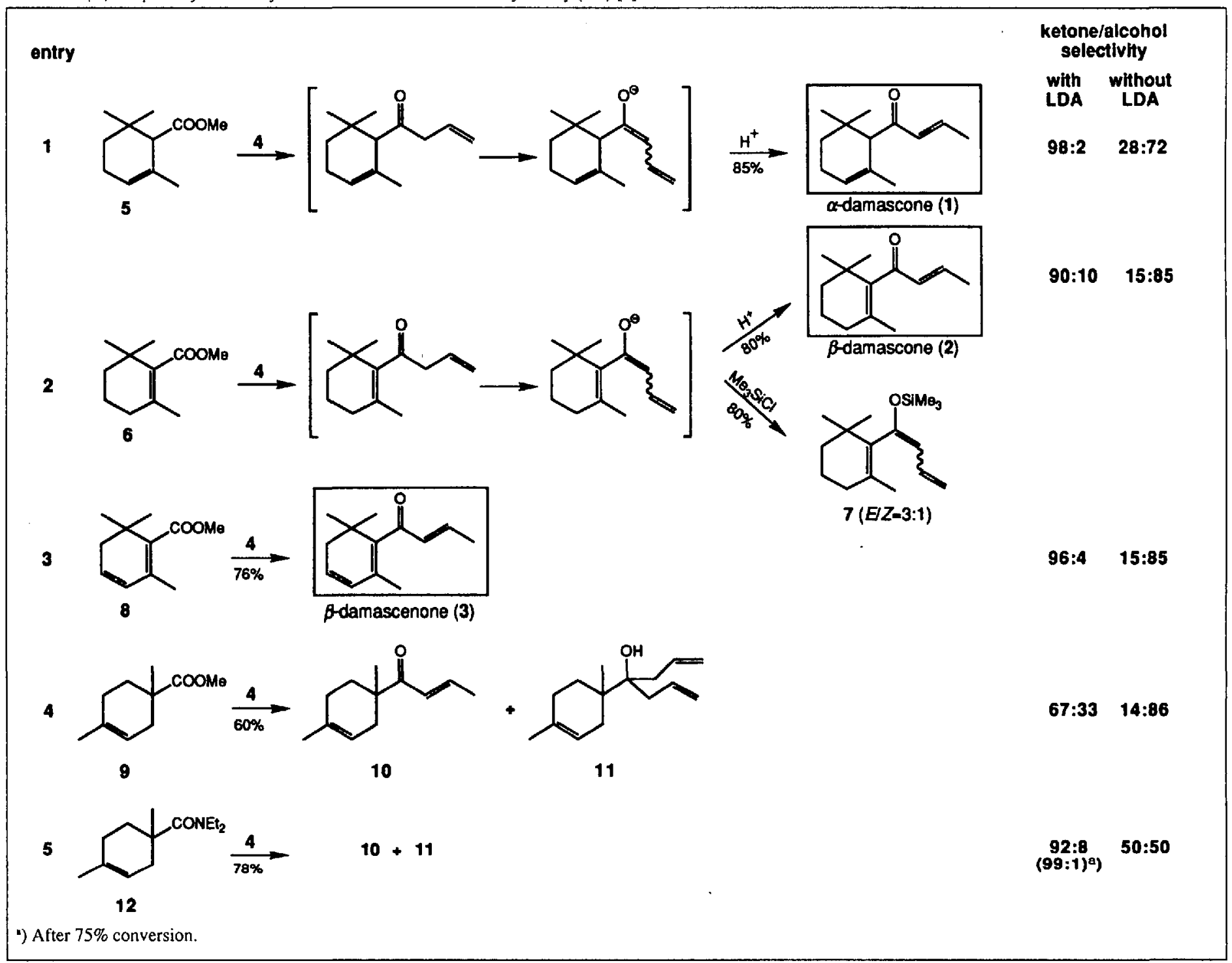

Scheme 2

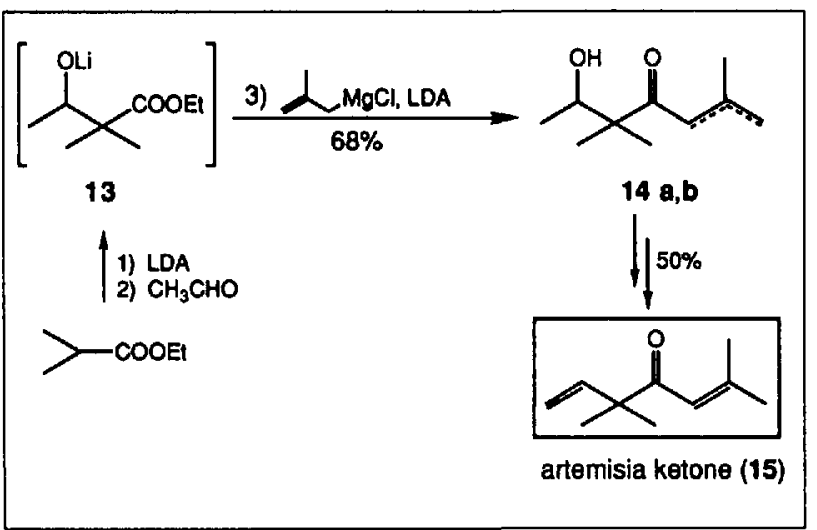

Scheme 3

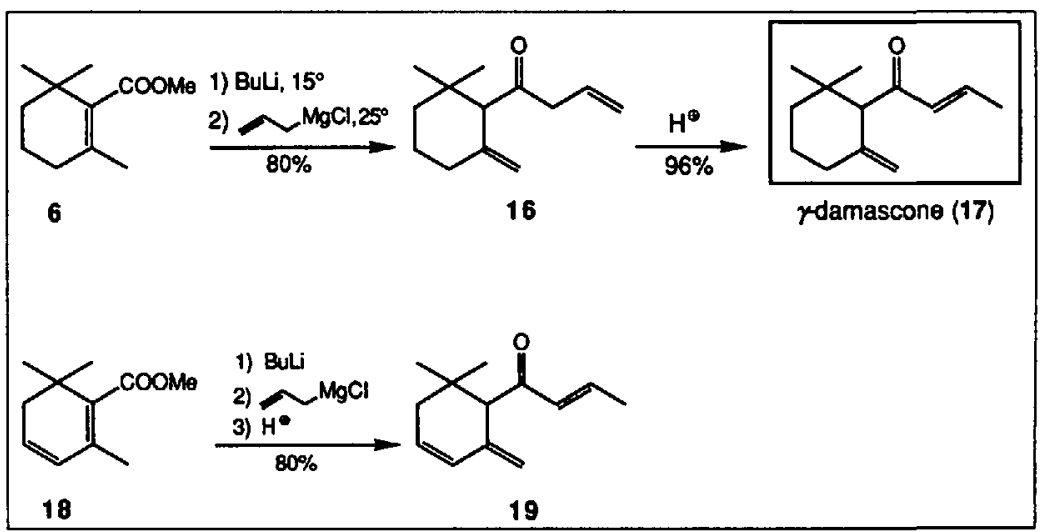


species 30 undergoes an intramolecular acylation [12].

On the other hand, it is also possible that the ester enolate $\mathbf{2 0}$ is only of limited stability and is converted - with concomitant loss of MeOLi - to the $\gamma$-ketene 25 (Scheme 6 ). The Grignard reaction with this putative ketene or its valence tautomer, cyclobutenone 26, would then possibly lead to ketone enolate 21. Indeed, according to Seebach et al. [13] (Scheme 7), when certain $\alpha$-disubstituted BHT esters are deprotonated with BuLi at $-78^{\circ}$, and $\mathrm{MeLi}$ is added, the enolate decomposes at $-20^{\circ}$ to the corresponding ketene. MeLi then attacks from the sterically less hindered side and the ( $Z$ )-ketone enolate is obtained with very high stereoselectivity. At present, we cannot be certain, if our reaction also proceeds via a ketene. Based on recent work, we tentatively conclude that the organometallic reagent is bonded by complexation to the ester enolate and thus contributes to the weakening of the acyl C$O$ bond. In a second step, the nucleophile then attacks the ester group or ketenoid species.

This transformation is not limited to allylic Grignard reagents. Scheme 8 shows examples of additions of vinylmagnesium bromide or PhLi on ester enolates $(6 \rightarrow 31$ and $5 \rightarrow 32$ ). Moreover, hydride additions allow the direct formation of aldehyde enolates, as exemplified by the efficient synthesis of safranal (33), an important constituent of saffron oil. The last example, the preparation of the artemisia ketone precursor 14 (Scheme 2) from thiol ester 34 by successive deprotonation, Grignard addition, and aldol reaction nicely illustrates that the described methodology is not limited to cyclogeranate esters.

Enantioselective Protonation of Ketone Enolates: Synthesis of $(+)-(R)-$ and $(-)$ $(S)$ - $\alpha$-Damascone

In the previous section, we have discussed the diastereoselective formation of ketone enolates which, upon protonation, lead to chiral, racemic ketones. We next turned our attention to the enantioselective synthesis of $(R)$ - and (S)- $\alpha$-damascone [14]. Our plan consisted of converting ester 5 via ester enolate 35 in a regio- and stereoselective manner into a ketone enolate 36 , and then to protonate the in situ generated enolate enantioselectively by means of an appropriate chiral proton source (Scheme 9). This would allow us to prepare both $(S)$ - and $(R)-\alpha$-damascone via a common achiral precursor 36 and to compare their organoleptic properties. In addition, we hoped to develop a novel procedure of general synthetic value.

As we have seen above, methyl $\alpha$-cyclogeranate (5) can be converted regioselectively into a $(E) /(Z)$-mixture of ketone enolates 38 , when the Grignard reaction is performed in the presence of LDA. This protocol is based on the rapid deprotonation of the in
Scheme 4

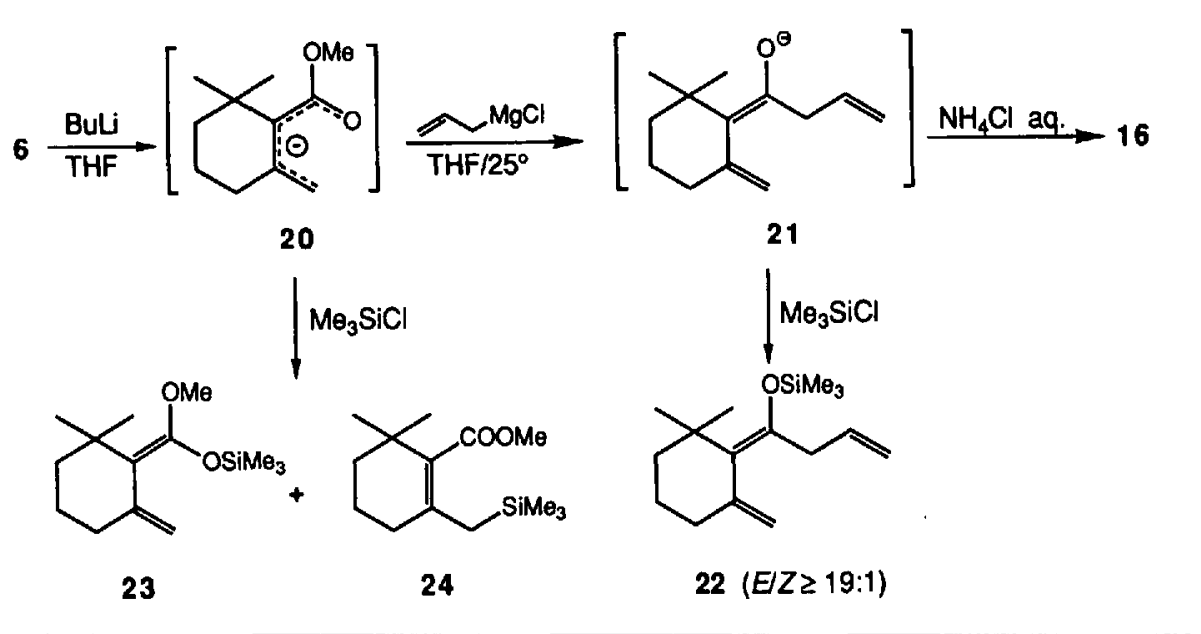

Scheme 5

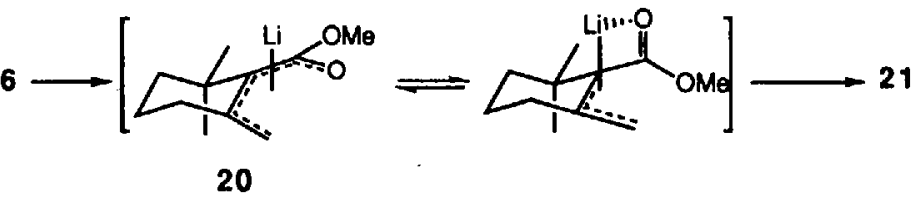

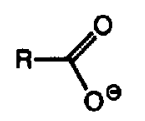

$27[9]$

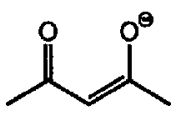

28 [10]<smiles>CCO[C@H](O)C=C1C(C)(C)CCCC1(C)C</smiles>

29 [11]

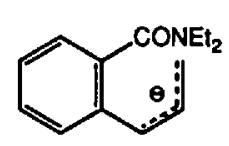

30 [12]
Scheme 6

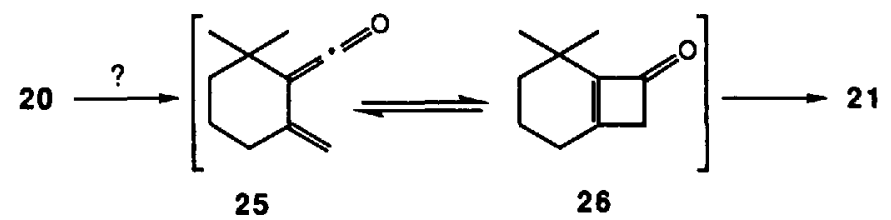

Scheme 7
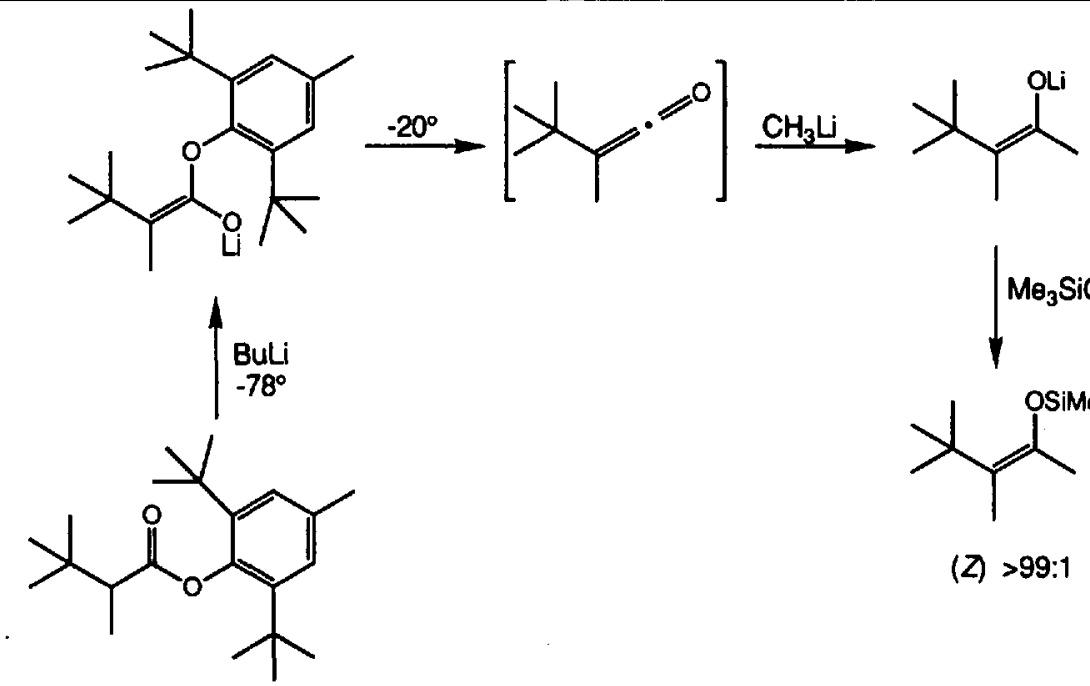

$\mathrm{Me} \mathrm{BiCl}_{3}$

1<smiles>COC(C)=C(C)C(C)(C)C</smiles>

(Z) $>99: 1$

Häner, Laube, and Seebach [13] 
Scheme 8

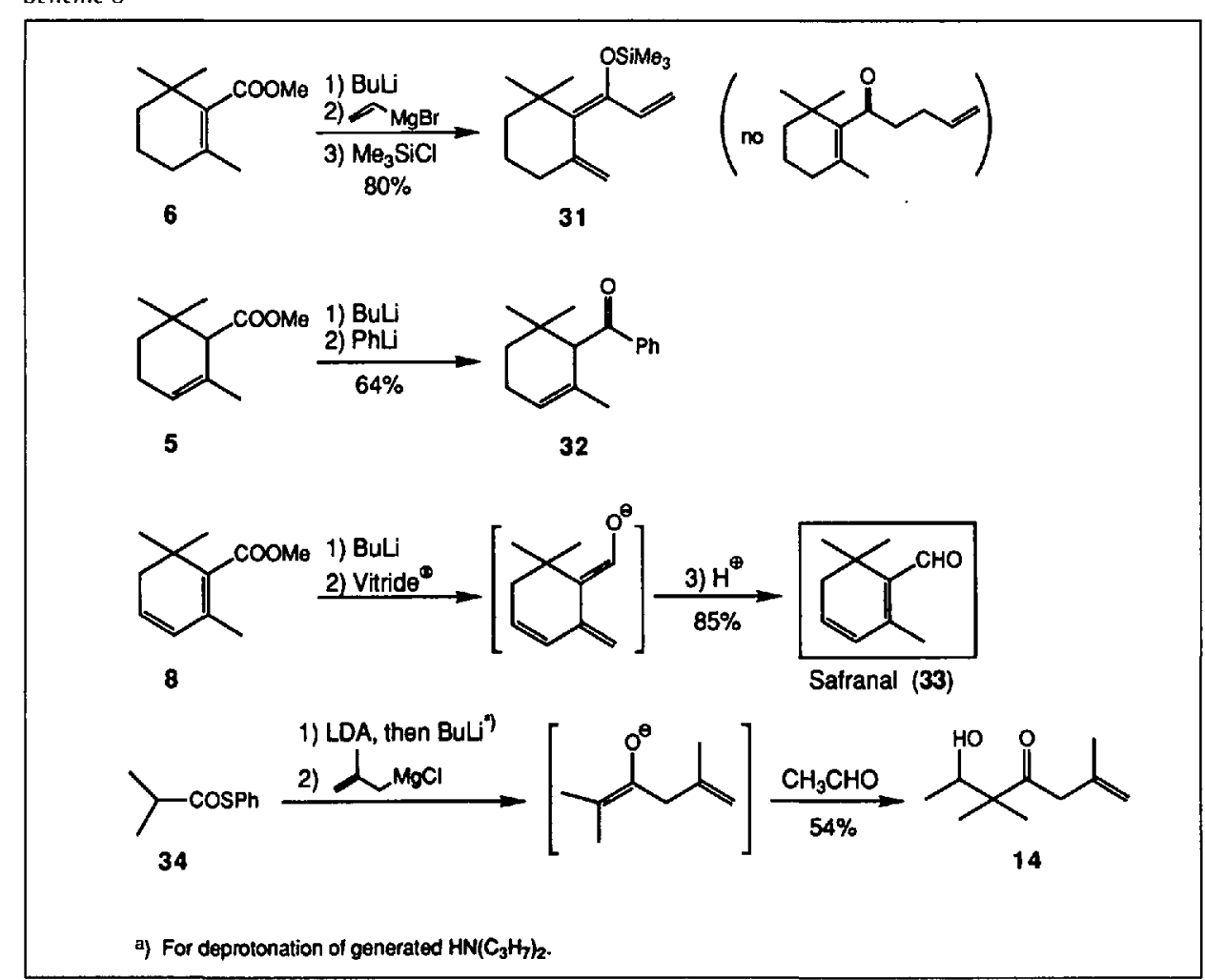

Scheme 9

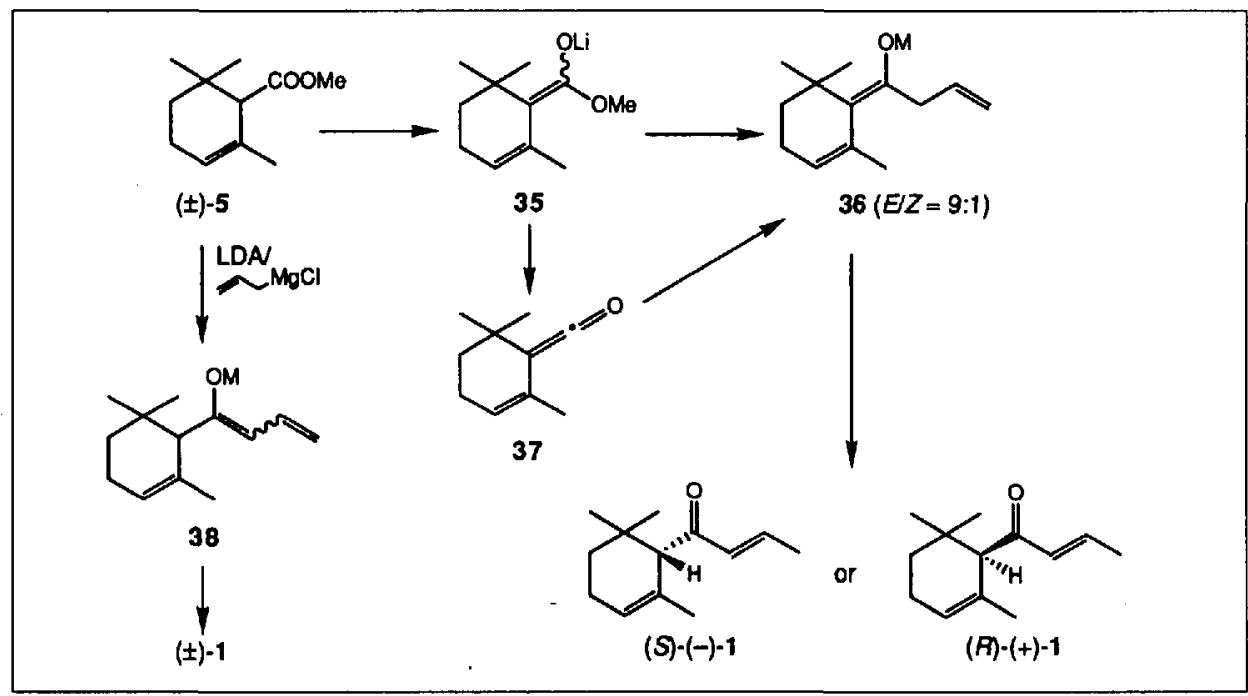

Scheme 10<smiles>COC(=O)C(P)/N=C/c1ccccc1</smiles><smiles></smiles>

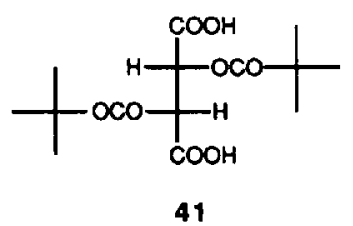

Duhamel at al. [16a]
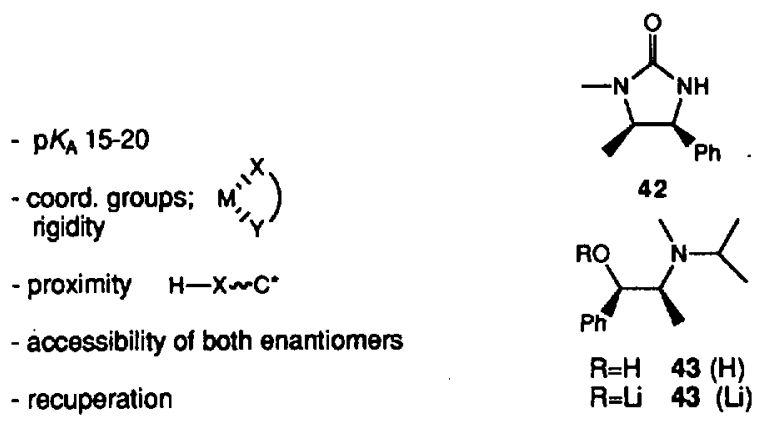

$R=L 3$ ن 4 (ن) situ generated ketone and cannot lead to optically active 1 . On the other hand, the isomeric ketone enolate 36, which is of interest for the enantioselective protonation, is obtained regio- and diastereoselectively as a 9:1 $(E) /(Z)$-mixture by deprotonation of methyl cyclogeranate (5) with BuLi followed by reaction of the resultant ester enolate $\mathbf{3 5}$ with allylmagnesium chloride. As shown above for the $\gamma$-damascone synthesis (Schemes 3-5), the reaction probably proceeds via a ketenoid species. Indeed, as has been shown by Näf and Decorzant [15], Grignard addition on the stable and easily accessible ketene 37 affords also a 9:1 (E)/ (Z)-mixture of enolate 36, as determined by silylation. We could now concentrate on the enantioselective protonation of this enolate.

Up to now, enantioselective protonation has met with limited success, and the rare examples which describe appreciable enantiomeric excesses of $50-70 \%$ are restricted to rigid ester enolates of defined configuration possessing supplementary heteroatoms capable of undergoing chelation and, ideally, a Ph group at the $C(\alpha)$ position [16][17]. In their pioneering work on the 'deracemization' of amino-acid derivatives 39 by enantjoselective protonation of the corresponding anions 40, Duhamel's group has developed $(2 R, 3 R)$-dipivaloyltartaric acid $(\mathbf{4 1})$ as favorite reagent [16a] (Scheme 10). We felt that a judicious choice of the chiral proton source would allow wider applicability for enantioselective protonation. $A$ priori, it seemed attractive to take into account the enolate structural requirements (see 40) for the design of the proton source. In the search for an efficient and synthetically useful chiral proton source, we were guided by the following criteria. Ideally, the chiral reagent should be only weakly acidic to allow better transition state discrimination ( $\left.\mathrm{p} K_{\mathrm{A}} 15-20\right)$. It should also contain electron-rich groups with coordination or chelation ability which would enhance conformational rigidity in the transition state. For obvious reasons, the transferred proton should be located in the proximity of the stereogenic center and, last but not least, the chiral reagent should be readily accessible in both enantiomeric forms and be easily recuperable. These criteria are fulfilled with the ephedrine derivatives $\mathbf{4 2}$ and 43 which, to our knowledge, have never been used for enantioselective protonation. The imidazolidinone $\mathbf{4 2}$ has an $\mathrm{N}-\mathrm{H}$ bond confined in a cyclic system, and the amino alcohol $43(\mathrm{H})$ can attain conformational rigidity through chelation. It should be added that $\mathbf{4 2}$ is commercially available, and that $43(\mathrm{H})$ is readily obtained from ephedrine with acetone and a reducing agent in analogy to published procedures [18].

In an initial experiment, ester 5 was deprotonated with BuLi [19] and the resultant ester enolate 35 was treated with allylmagnesium chloride to afford ketone enolate 36 $(E / Z \sim 9: 1)$. Protonation of 36 with (+)-42 or $(-)-43(\mathrm{H})$ (Scheme 11 ), and subsequent isomerization of the terminal double bond 
with alumina gave $(-)-(S)-1(60 \%)$ with $58 \%$ ee and $70 \%$ ee, respectively. In contrast, protonation of 36 with $(2 R, 3 R)$-dipivaloyltartaric acid $(\mathbf{4 1})$ provided $(-)-(S)-1$ with an ee of only $8 \%$.

To better understand the influence of the counter ion and ligand and to avoid the use of BuLi [19], we next investigated the reaction of allylmagnesium chloride with ketene 37. The thus formed THF-solvated but otherwise ligand-free enolate 36 was protonated with amino alcohol $43(\mathrm{H})$. Much to our surprise, protonation of the ligand- and $\mathrm{Li}$ free enolate 36 afforded $(+)-(R)-1(16 \%$ ee) as the major enantiomer. On the other hand, addition of $\mathrm{l}$ equiv. of $\mathrm{MeOLi}$ prior to protonation, thus restoring the conditions present when starting from ester 5 , furnished (-)-(S)1 with $70 \%$ ee. Next, enolate 36 was treated with the chiral lithium alkoxide $43(\mathrm{Li})$, derived from isopropyl ephedrine and protonated with $43(\mathrm{H})$ to afford $(S)$ - $\alpha$-damascone with $84 \%$ ee and a yield of $73 \%$. Likewise, use of the enantiomeric ephedrine derivative afforded $(R)$ - $\alpha$-damascone with $84 \%$ ee. These results represent the highest ee yet

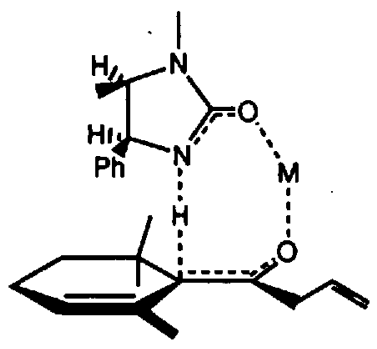

A

CHIMIA 45 (1991) Nr. 9 (September)

reported for enantioselective enolate protonation and can be considered to be the result of double stereodifferentiation [20]. If the formation of a chiral complex between $\mathrm{Mg}$ enolate and $\mathrm{Li}$-alkoxide is a prerequisite for high enantioselectivity, then protonation of a chiral complex with an achiral proton

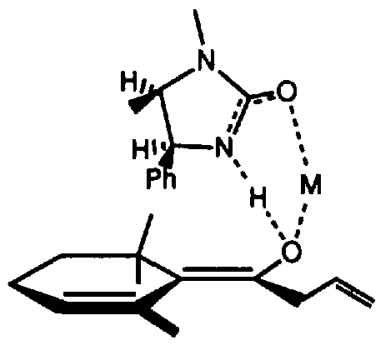

B

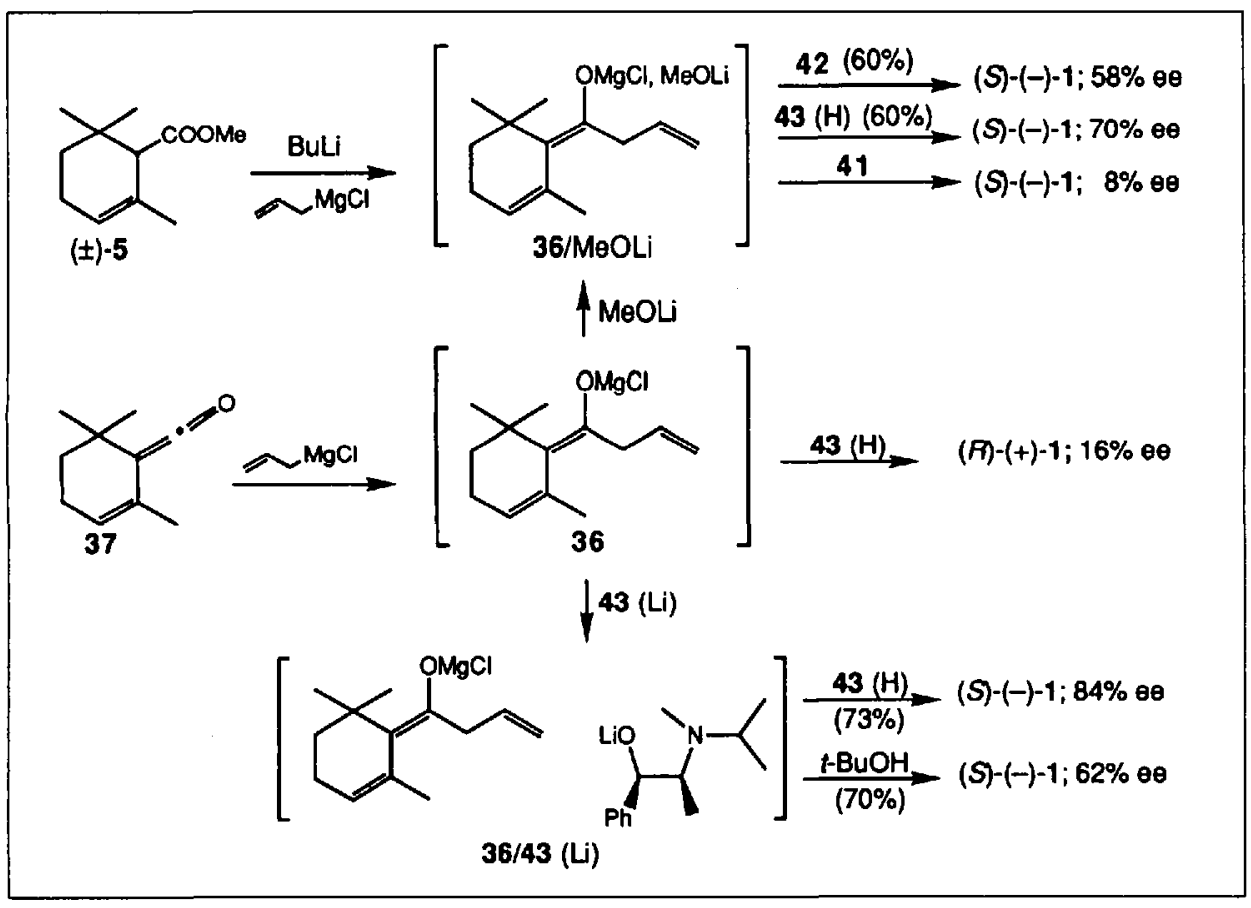

source should also lead to chirality induction. Indeed, protonation of the same chiral enolate complex $36 / 43(\mathrm{Li})$ with $t-\mathrm{BuOH}$ led to $(-)-(S)-1$ with $62 \%$ ee.

In sharp contrast to the results obtained with isopropyl ephedrine $43(\mathrm{H})$, protonation of enolate 36 with urea 42 gave consistent enantiofacial discriminations ranging between 50 and $60 \%$ ee independent of the presence or the absence of $\mathrm{Li}$ (or $\mathrm{MgCl}$ ) and ligand. The transition structures $\mathbf{A}$ and $\mathbf{B}$ would be compatible with the observed absolute configuration. If one assumes complexation between the enolate and the carbonyl group, the approach of the $\mathrm{NH}$ group is clearly favored from the $R e$ face. In the event that the proton in a first step approaches the enolate $\mathrm{O}$-atom, a similar transition state could be expected.

Concerning the mechanism of protonation of the chiral enolate complex 36/43(Li) with isopropyl ephedrine $(43(\mathrm{Li}))$, the present investigations do not yet allow us to draw

Scheme 12<smiles>CC(=O)C(C)(C)CCO[Si](C)(C)C(C)(C)C</smiles>

Williard and Hintze [21]

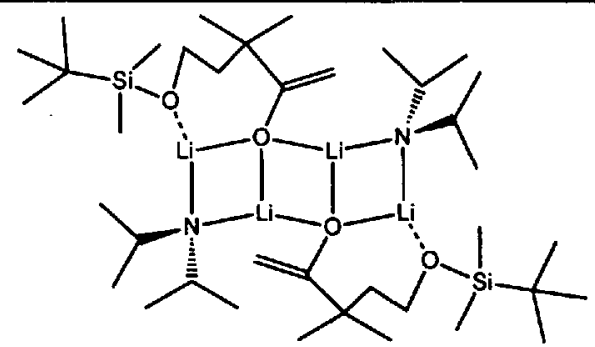

44

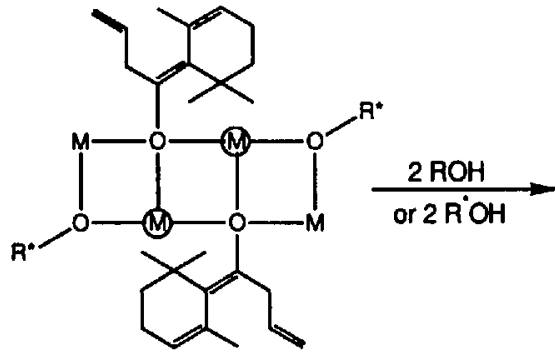<smiles>C=CCC(C1ONOC1O)C1C(C)CCCC1(C)O</smiles>

(ROM)



47



48 
Scheme 13

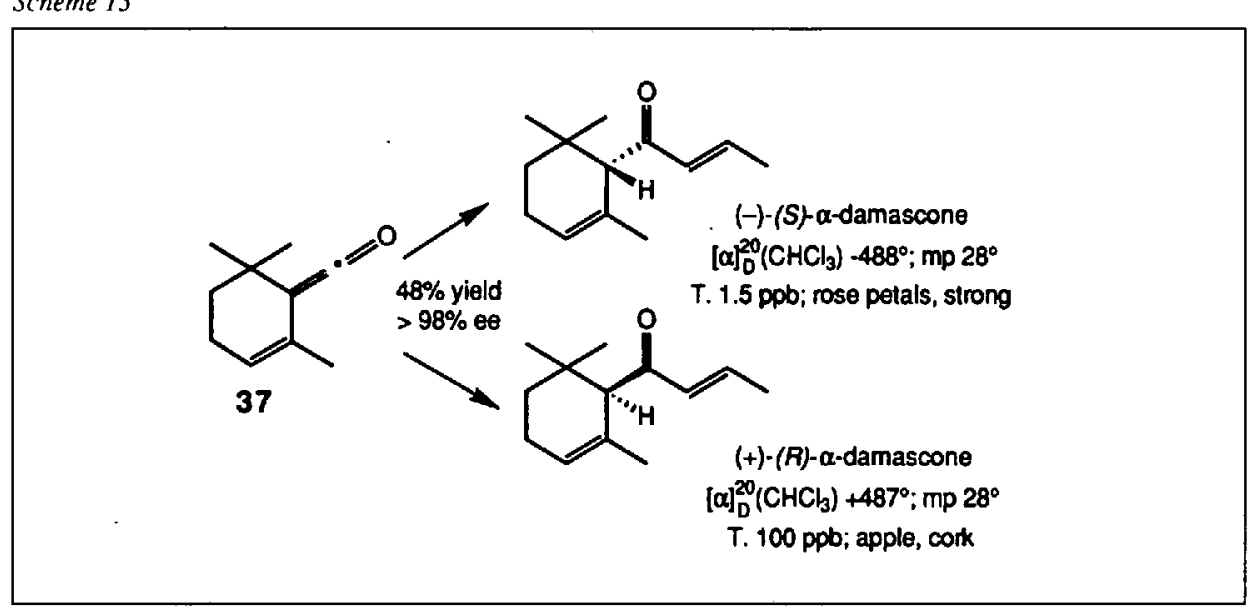

Scheme 14

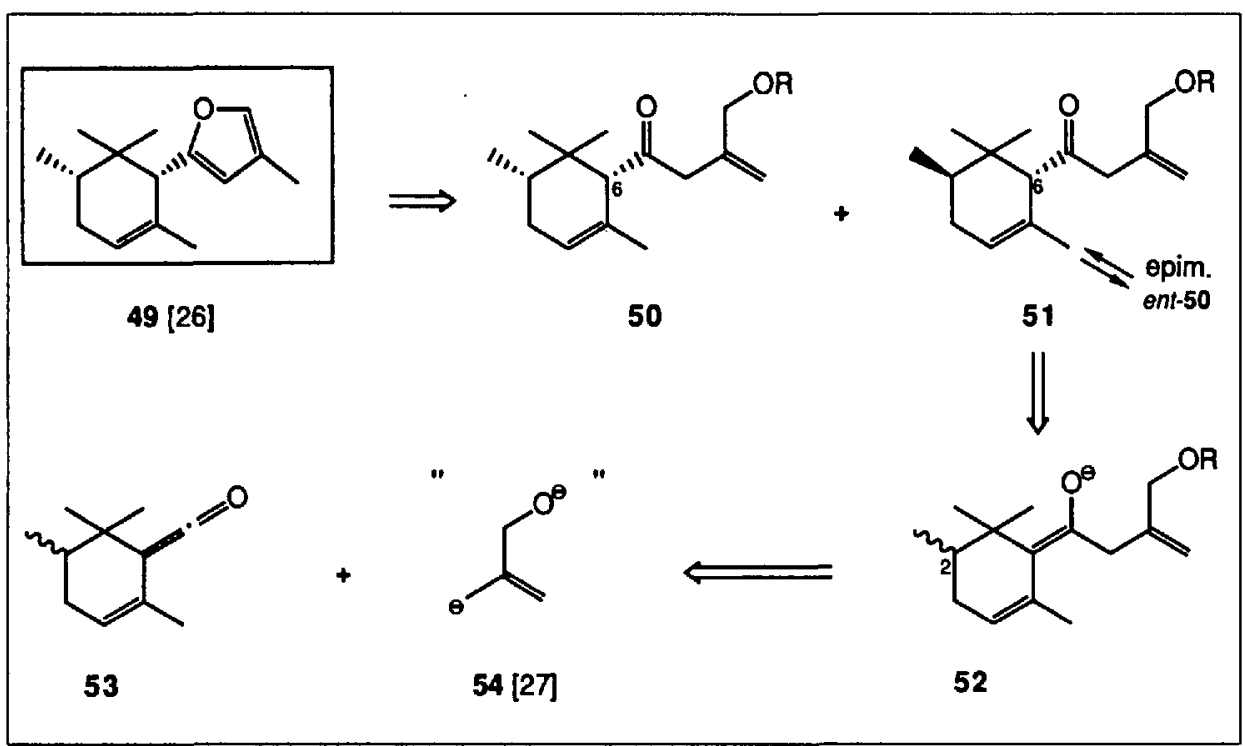

Scheme 15

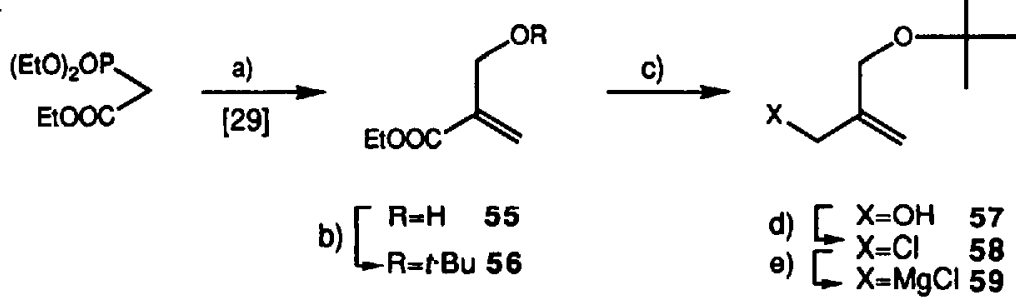

Reagents: a) $\left(\mathrm{CH}_{2} \mathrm{O}\right)_{n}, \mathrm{~K}_{2} \mathrm{CO}_{3}(66 \%)$ b) $\mathrm{Me}_{2} \mathrm{CCH}_{2}$, Amberlyst $15(89 \%)$ c) $\mathrm{LAlH}_{4}, \mathrm{ACl}_{3}(88 \%)$ d) $\mathrm{CCl}_{4} \mathrm{PPh}_{3}(61 \%)$ e) $\mathrm{Mg}$, THF (in situ)

Scheme 10<smiles>C=C(COC(C)(C)C)CC(OC)=C1C(C)=CCCC1(C)C</smiles>

37<smiles>CC1=CCCC(C)(C)[C@H]1c1cc(C)co1</smiles>

$60(80 \% \theta \theta)$ definitive conclusions. Inspired by Williard's $\mathrm{X}$-ray analysis of a dimeric mixed aggregate 44 between a ketone enolate and LDA [21], we postulate that, in our case, a similar ladder-type aggregate 45 is formed (Scheme 12). Replacement of two metal centers by protons would lead to a de-aggregated monomeric complex 46 (or 47,48 ), a hybrid between enol and enolate, in which the chiral information, necessary for the subsequent irreversible proton transfer, is still complete.

Let us now turn back to the facts, i.e. the measured $84 \%$ ee of $(-)-(S)-1$ and $(+)-(R)-1$ [22]. In this state of purity, these enantiomers crystallized in pentane, and both enantiomerically pure $(S)$ - and $(R) \alpha$-damascone could, therefore, be obtained in $48 \%$ yield from the common achiral precursor 37 [23] (Scheme 13). The organoleptic evaluation of the two enantiomers has shown that $(S)-\alpha$ damascone is by far the more precious and powerful fragrance. Its odor is reminiscent of rose petals, whereas the $(R)$-enantiomerhas a more pronounced apple note and is also responsible for the undesired cork smell. The difference of threshold values is also remarkable. Whereas the odor of the $(S)$ enantiomer is still perceived at a concentration of $1.5 \mathrm{ppb}$, the $(R)$-antipode requires a 70 times higher concentration for odor perception [24]. Interestingly, the $(S)$-enantiomer is also the naturally occurring one [25].

As an application of enantioselective protonation, the uncompleted synthesis of $\alpha$-iris furan (49), recently discovered in iris oil [26], is briefly discussed (Scheme 14). As its absolute configuration was only tentatively assigned, we envisaged an enantioselective route to this furan.

Our retrosynthetic analysis leads to precursor 50, which has the correct oxidation level and would be accessible by a Grignardtype addition of dianion 54 [27] - or an equivalent - on racemic ketene 53, followed by an enantioselective protonation of the racemic enolate 52 . If it appears that the directing effect of the chiral proton donor is much more important than the influence of the $\mathrm{C}(2) \mathrm{Me}$ group, we would expect the enantioselective formation - with respect to stereogenic center $C(6)$ - of a diastereoisomeric mixture of the two ketones $\mathbf{5 0}$ and $\mathbf{5 1}$. The enantiomer of $\mathbf{5 0}$ could be obtained by epimerization of the trans-ketone 51. Another possibility would be kinetic resolution, by enantioselective protonation of $50 \%$ of the racemic enolate $\mathbf{5 2}$, followed by silylation of the unreacted enolate.

As preliminary experiments with the dilithio dianion $\mathbf{5 4}$ led to product mixtures, we directed our efforts to a Grignard reaction with an $O$-protected allylic magnesium chloride such as 59 (Scheme 15). We expected the $t$-Bu group to be an ideal protecting group for two reasons: firstly the shielded oxygen should not inhibit the formation of the Grignard reagent [28], and secondly, subsequent deprotection should be straightforward. The synthesis of $\mathbf{5 8}$ involves $t$ butylation of the readily accessible hydroxy 


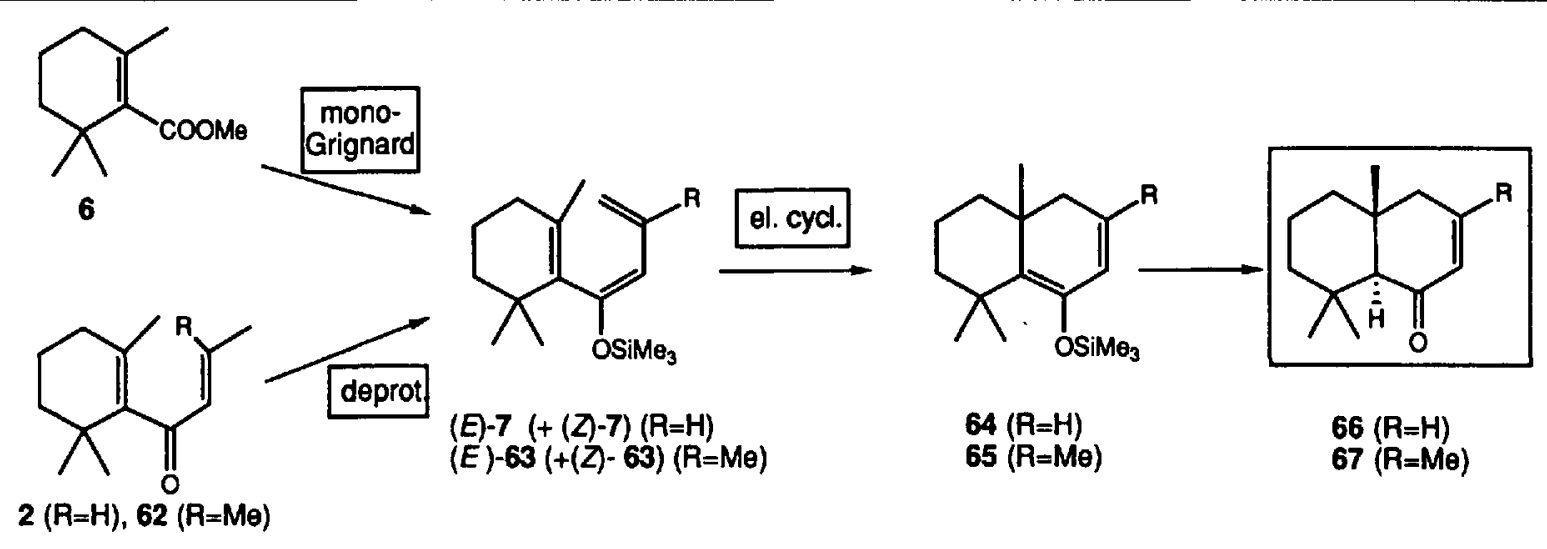

ester 55 [29], reduction of ester 56 with Li$\mathrm{AlH}_{4}$ and $\mathrm{AlCl}_{3}[30]$ and chlorination of $\mathbf{5 7}$. The Grignard reaction was tested on the known trimethylketene 37. As expected formation of the Grignard reagent in THF was facile, and its reaction with ketene $\mathbf{3 7}$ gave the desired ketone enolate (Scheme 16). Complexation with the chiral lithium alkoxide $43(\mathrm{Li})$ and protonation with $43(\mathrm{H})$ then afforded the furan precursor 60 with $80 \%$ ee and a yield of $85 \%$. Its absolute configuration is presently being verified by conversion into a compound of known configuration. In addition, preliminary experiments have allowed the preparation of furan 61 in $\sim 60 \%$ yield, thus allowing us to envisage with confidence the synthesis of its methyl homolog 49.

From Damascones to Decalones:

Diastereocontrolled Synthesis of Functionalized trans-Decalins via Electrocyclic Reaction of Trienol Ethers

In the synthesis of $\beta$-damascone (2) from methyl $\beta$-cyclogeranate (6) (Scheme 1), we had shown that the resultant enolate can also be trapped with $\mathrm{Me}_{3} \mathrm{SiCl}$, thus giving rise to a 3:1 mixture of $(E)$ - and $(Z)$-enol-silyl ethers 7. In this last section we shall discuss the thermal electrocyclic reaction of $(E)-7$ (or $(E)-63$ which opens a direct access to trimethyl-trans-decalins 66 (or 67) (Scheme 17).

For several reasons, this scheme seemed to us very attractive: a large number of trimethyl-trans-decalins exhibiting diverse biological activities are known. As representative examples, Polywood ${ }^{\mathbb{B}}(\mathbf{6 8})[31][32]$ and $A m b r o x^{(1)}$ (69) [31][33] with their outstanding woody and ambergris odor qualities constitute famous target molecules in perfumery (Scheme 18). Cinnamodial (70) [34] possesses insect antifeedant activity and triggers off a peppery taste on the human tongue, whereas forskolin (71) [35] shows very promising pharmacological activities [36]. Interestingly, the two decalones 66 and 67 were hitherto unknown. As they can be considered as bicyclic analogs of the damascones, we were interested to know whether their odor properties would be da-

Scheme 18<smiles>CC(=O)O[C@H]1CC[C@@H]2C(C)(C)CCC[C@]2(C)C1</smiles>

68<smiles>CC1(C)CCC[C@]2(C)[C@H]1CC[C@]1(C)OCC[C@H]12</smiles>

69<smiles>CC1(C)CCCC2(C)C1[C@H](O)C(C=O)C[C@H]2O</smiles>

70



71

Scheme 19<smiles>C=CC1=C(C=C)C(C)(C)CCC1OC(=O)C1CCCCC1</smiles>

72<smiles>[3H]C#CC(=O)O[C@H]1CCC(C)(C)C(C(=C)OCC)=C1C</smiles>

75

Corey ef al. [39][38b]<smiles>C#CCC1(C)CC2OC(=O)C3=C(C)CC=CC32C1</smiles>

73<smiles>[Y6]C1(C)CC[C@H](OC(=O)c2ccccc2)[C@@]2(C)[C@H](C(C)=O)C(C)=CC(=O)[C@]12C</smiles>

74<smiles>C=CC1CC[C@H]2OC(=O)C3=C(C)CC(OCC)=C(C)C32C1(C)C</smiles>

76

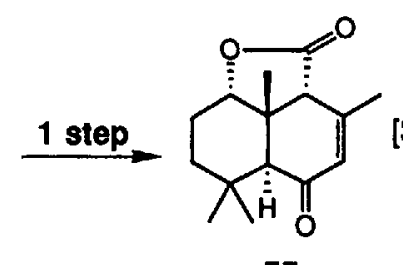

[38b] mascone-like or more closely related to the woody decalins. In fact, we were not too surprised that these decalones were new, because their putative construction by classical methods [37] would be necessarily lengthy.

In addition, our planned strategy would also be of interest for the synthesis of forskolin (71) or a precursor thereof (e.g. 77, Scheme 19), as the C(6) O-functionality is introduced directly in the ring-forming step. Most published syntheses in this field suffer from the fact that the oxygen has to be introduced with difficulty into the sterically hindered $C(6)$ position of a preformed decalin [38]. This conceptual problem was also encountered by Corey et al. [38b][39].
Scheme 19 illustrates two recent syntheses of forskolin intermediates which are based on an intramolecular Diels-Alder reaction. For the first synthesis, seven steps were necessary to convert lactone 73 into the $C(6)$ functionalized ketone 74 [39]. The second route avoids this problem by using a $\mathrm{C}(6)$ functionalized diene $\mathbf{7 5}$ for the intramolecular Diels-Alder reaction. The tricyclic carbonate 76 was then converted directly to the desired ketone 77 [38b].

In a first experiment, we pyrolyzed enol ethers $7(E / Z 3: 1)$ at $365^{\circ}$. Besides recovered $(Z)-7$, we isolated as main product the desired decalin 64 (Scheme 17) together with small amounts of two rearrangement products (78 and 79, Scheme 20). This result en- 


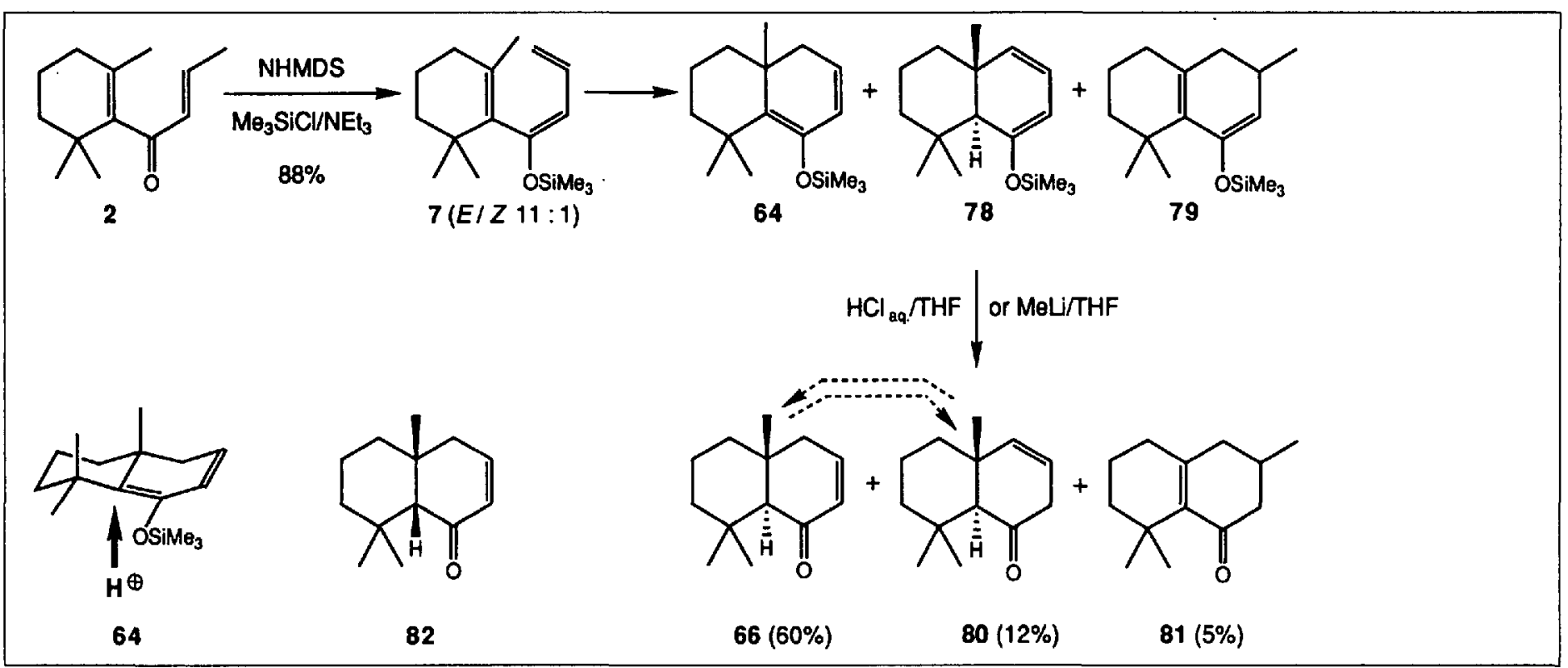

Scheme 21



couraged us to look for a more selective access to triene $(E)-7$. Therefore, we turned our attention to the deprotonation of $\beta$-damascone (2). However, deprotonation of 2 with LDA was only moderately selective (E/Z 2.7:1) and in addition, the Michael reaction of LDA on the enone side chain of 2 became the major pathway. This competing 1,4-addition could be avoided completely, when LDA was replaced by the less nucleophilic lithium bis(trimethylsilyl)amide (LHMDS). Under these conditions, a 7:1
$(E / Z)$ selectivity was obtained, and the distilled yield of 7 amounted to $93 \%$. With sodium bis(trimethylsilyl)amide(NHMDS) the selectivity could even be improved to 11:1. This preferential formation of the $(E)$-trienol ether results from the s-trans-conformation of the enone side chain. As the enone moiety of $\mathbf{2}$ is known to be twisted out of the cyclohexenyl $\pi$-system for steric reasons [8], the shown s-trans-conformation does not suffer from nonbonding interactions.

The electrocyclic reaction sequence



2

starting from $\beta$-damascone $(2)$ is presented in Scheme 20. Due to a better $(E) /(Z)$ ratio of 7 , the conversion could be improved, and after mild desilylation, ketones 66,80 , and 81 were isolated in good yields.

Under more acidic conditions desilylation afforded 66 almost exclusively (72\%) [40]. On the other hand, the deconjugated enone 80 was formed as the sole product upon deprotonation of $\mathbf{6 6}$ using NHMDS, followed by protonation. The kinetically controlled desilylation-protonation takes place in a higly stereocontrolled manner with axial introduction of the proton from the sterically less hindered face. Less than $2 \%$ of the more stable cis-decalin $\mathbf{8 2}$ could be detected. However, 82 could be obtained

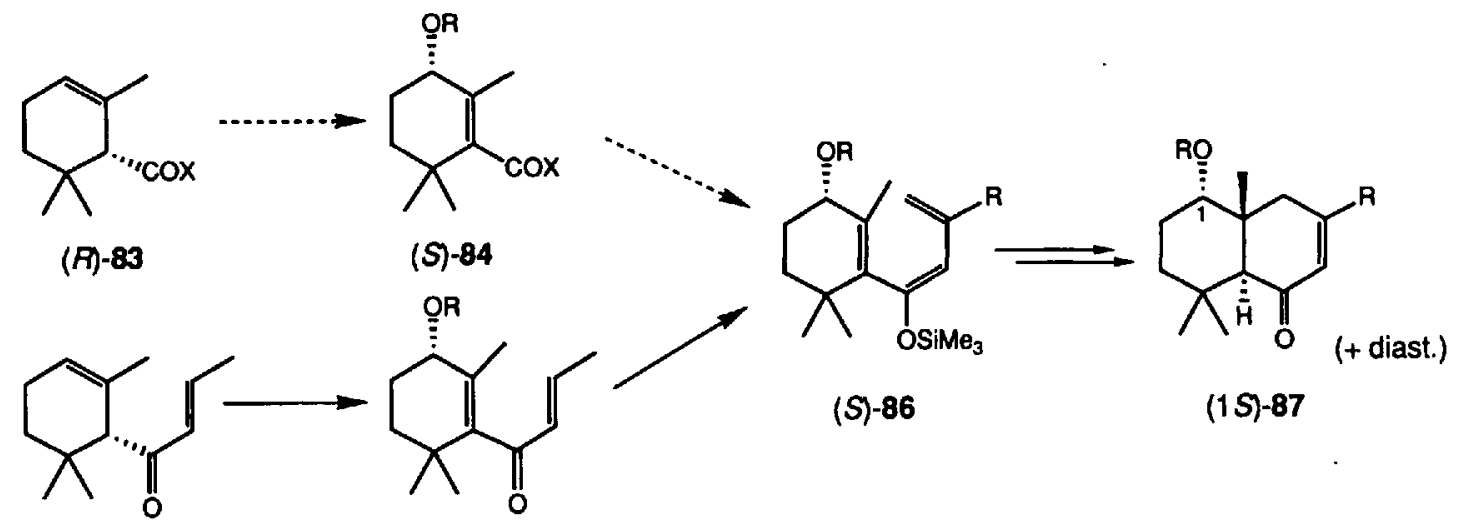

(R)- $\alpha$-damascone (1)

(S)-85 
by epimerization of the trans-decalin 66 under forcing conditions: a toluene solution containing 1 equiv. of $\mathrm{TsOH}$ was heated at reflux for $24 \mathrm{~h}$.

For the synthesis of tetramethyl decalin 67 (Scheme 17), the triene mixture 63 (E/Z 2.2:1), obtained from ester 6 , was pyrolyzed at $365^{\circ}$ to afford, after acid treatment, the target molecule free of any rearrangement products in a global yield of $30 \%$ [40].

Scheme $2 l$ should confirm that we have not forgotten the industrial motivation of this work. The two new decalones 66 and 67 [40] were submitted to our perfumers for organoleptic evaluation. Both compounds show very interesting, original odor profiles. Whereas both a woody and a typical damascone note are present in the trimethyldecalone, the tetramethyl decalone has a more pronounced woody character [41].

The other aspect of this work, the synthesis of forskolin - hopefully in enantiomerically pure form - is also being pursued. The basic idea consists in converting $(R)-\alpha$-damascone (1) [23] by a chirality transfer reaction into enantiomerically pure 4-hydroxy$\beta$-damascone $((S)-85, \mathrm{R}=\mathrm{H})$. Likewise, chirality transfer of ester $(R)-83$ should give easy access to hydroxy ester $(S)-84$ (Scheme 22). The advantages of this approach are twofold. Firstly, the electrocyclic reaction of an O-functionalized trienol ether of type $\mathbf{8 6}$ would allow the introduction of the required C(1) O-function, secondly it would directly lead to enantiomerically pure decalones of type 87.

Our results will be reported in due course, but it can be already revealed that the chirality transfer $(R)-1 \rightarrow(S)-85$ has succeeded with an enantiomeric excess of $96 \%$; in addition preliminary experiments indicate that the electrocyclic reaction can indeed be extended to 4-O-functionalized trienol ethers.

I should like to thank Prof. A. Eschenmoser, $W$ Oppolzer, and $D$. Sechach for highly appreciated stimulating and encouraging discussions. I should also like to express my gratitude to my co-workers who combine the talents of critical thinking with considerable experimental skill: J. Galindo, who was recently promoted to research assistant due to his excellent qualifications, has accomplished almost alone the whole damascone enolate chemistry and $O$. Guntern, who has enthusiastically developed the new decalin syntheses in a remarkably short period of time. Finally I would like to acknowledge my colleagues, in particular Dr. G. Ohloff Dr. F. Näf, Dr. K. H Schulte-Elte Dr. B Maurer. Dr. R. Snowden, Dr. B. Winter, and Dr. C. Chapuis for their deep engagement to original research and their continual interest in our projects.
Received: March 25, 1991

[1] K.H.Schulte-Elte, Ger. Offen. 2,305, 140 (prior 3.2.1972) (CA: 1973, 79, 115743 t); R. L. Snowden, S. M. Linder, B. L. Muller, K. H. Schulte-Elte, Helv. Chim. Acta 1987, 70, 1858.

[2] C. Fehr, J. Galindo, Helv. Chim. Acta 1986, 69, 228.

[3] For a related $\beta$-damascenone synthesis, using allyl-Li, see: G. Büchi, H. Wijest, Helv. Chim. Acta 1971, 54,1767.

[4] The diethylamides corresponding to esters 5,6 , and $\mathbf{8}$ are unreactive.

[5] C. Fehr, J. Galindo, R. Perret, Helv. Chim. Acto 1987, 70, 1745.

[6] K. H. Schulte-Elte, V.Rautenstrauch, G. Ohloff, Helv. Chim. Acta 1971, 54, 1805; K. H. SchulteElte, B. L. Muller, G. Ohloff, ibid. 1973,56,310; F. Näf, R. Decorzant, ibid. 1974, 57, 1317; 0 . Takazawa, K. Saigo, K. Narasaka, Chem. Lett. 1977, 757; M. Zaidlewicz, Tetrahedron Lett 1986, 27, 5135; P. Gosselin, ibid. 1986, 27, 5495; A. Amrollah-Madjdabadi, L. Stella, $B u l l$. SoC. Chim. Fr. 1987, 350; R. L. Snowden, S. M. Linder, Hel'. Chim. Acta 1988, 71,1587.

[7] C. Fehr, J. Galindo, J. Org. Chem. 1988, 53, 1828

[8] For analogous cases: see [3] and M. Klein, U. Wingen, V. Buss, J. Am. Chem. Soc. 1987, 109 , 6486.

[9] M. J. Jorgensen, Org. React. (N. Y.) 1970, /8, 1.

[10] A. Barabas, A. T. Balaban, Tetrahedron 1971,27, 5495.

[11] Ae. de Groot, P. M. van Leeuwen, N. H. G Penners, B. H. Koning, Recl. Trav. Chim. PaysBas 1978, 97, 124.

[12] H.P.Sibi, J. W. Dankwardt, V. Snieckus, J.Org Chem. 1986, 5I, 271 .

[13] R. Häner, T. Laube, D. Seebach, J. Am. Chem. Soc. 1985, 107, 5396.

[14] G. Ohloff, G. Uhde, Helv' Chim. Acta 1970, 53, 531.

[15] F.Näf,R. Decorzant, Tetrahedron 1986,42,3245

[16] a) L. Duhamel, P. Duhamel, J. C. Lannay, J. C. Plaquevent, Bull.Soc. Chim. Fr. 1984, I[-421; L Duhamel, J. C. Plaquevent, J. Am. Chem. Soc. 1978, 100, 7415; L. Duhamel, S. Fouguay, J. C. Plaquevent, Tetrahedron Lett. 1986, 27,4975; L. Duhamel, J. C. Plaquevent, Bull. Soc. Chim. Fr. 1982, II-75; L. Duhamel, J. C. Plaquevent, Tetrahedron Lett. 1980, 21, 2521; b) F. M. Stoyanovich, E. P. Zakharov, Y. L. Gol'dfarb, M. M. Krayushkin, /zv. Akad. Nauk SSSR, Ser. Khim. 1986,1455; Chem. Abstr. 1987, 106. $49586 \mathrm{~s} ;$ U. Gerlach, S. Hünig, Angew. Chem. 1987, 99, 1323. For an enantioselective enolketone tautomerization ( $80 \%$ ee): L. Duhamel J.-C. Launay, Tetrahedron Lett. 1983, 24, 4209.

[17] For recent enantioselective protonations with ee's up to 91\%: O. Piva, J.-P. Pete, Tetrahedron Lett. 1990, 3I, 5157; D. Potin, K. Williams, J. Rebek, Jr., Angew. Chem. 1990, I02, 1485.

[18] J. E. Saavedra, J.Org. Chem. 1985, 50, 2271; R J. Adamski, S. Numajiri, U.S. Patent 386065 (prior. 23.10.1969 (CA: 1975, 82,170330t; $[\alpha]_{\mathrm{D}}^{20}$ $\left(\mathrm{CHCl}_{3}, c 6\right)-2.1^{\circ}$ or $+2.1^{\circ}$; b.p. $90^{\circ} / 0.05$ Torr

[19] To ensure complete deprotonation of 5 , a $20 \%$ excess of BuLi was employed; however, under these conditions, the formation of undesired 2,6,6-trimethylcyclohex-2-en-1-yl-1 pentanone $(\sim 10 \%)$ could not be completely avoided.

[20] Taking into account the diastereoisomericexcess of enolate 36 ( $80-85 \%$ de) the obtained ee's of 1 are excellent. Ongoing investigations in our laboratory have resulted in ee's higher than 95\%. The analogous $\mathrm{Mg}$-free Li complex shows lower enantiofacial discrimination (65\% ee), and the lithium-free magnesium complex is ineffective $(10 \%)$.

[21] P. G. Williard, M. J. Hintze, I. Am. Chem. Soc. 1987, 109, 5539; see also: P. G. Williard, G. J MacEwan, ibid. 1989./1/,7671; P. G. Williard, M. J. Hintze, ibid. 1990, $1 / 2,8602$.

[22] The enantiomeric excesses were determined by NMR with $\mathrm{Eu}$ (hfbc) ${ }_{3}$ shift reagent and by enantioselective GC using permethylated $\beta$ cyclodextrin in $O \mathrm{~V} \cdot 170 \mathrm{I}$ as chiral stationary phase.

[23] C. Fehr, J.Galindo, J.Am.Chem. Soc. 1988, IIO,

[24] C. Fehr, J. Galindo, Eur. Patent application No. 0326869 (prior, 5.2.1988)

[25] W. A. König, P. Evers, R. Krebber, S. Schulz, C. Fehr, G. Ohloff, Tetrahedron 1989, 45, 7003.

[26] B. Maurer, A. Hauser, J.-C. Froidevaux, Hels. Chim. Acta 1989, 72, 1400.

[27] B. M. Trost, D. M. T. Chan. J. Am. Chem. Soc 1979, 101, 6429; B. M. Trost, D. M. T. Chan, T. N. Nanninga, Org. Synth. 1984, 62, 58 .

[28] D. J. Collins, A. M. James, Aust J Chem 1989. 42,223 . For a closely related Grignurd reagent: J. v. d. Louw, J. L. v. d. Baan, F. Bickelhaupt, G. W. Klumpp, Tetrahedron Lett. 1987, 28, 2889.

[29] R. Villieras, M. Rambaud, Synthesis 1982. 924.

[30] See for example: J. K. Gawronski, H. M. Walborsky, J. Org. Chem. 1986, 51, 2863. In the absence of $\mathrm{AlCl}_{3}$ the saturated alcohol is obtained.

[31] G. Ohloff, in 'Fragrance Chemistry', Ed. E. T. Theimer, Academic Press, New York, 1982, p. 535; G. Ohloff, B. Winter, C. Fehr, 'Perfumes: Art, Science and Technology', Eds. P. M. Müller and D. Lamparsky, Elsevier Applied Science Publ., Amsterdam, 1991, p. 287.

[32] R. L. Snowden, S. M. Linder, M. Wüst, Helv. Chim. Acta 1989, 72, 892; A. Gautier, C. Vial, C. Morel, M. Lander, F. Näf, ibid. 1987, 70, 2039; G. Ohloff, F. Näf, R. Decorzant, E. Thommen, E. Sundt, ibid. 1973, 56,1414.

[33] G. Buchi, H. Wüest, Helv. Chim. Acta 1989, 72, 996; T. Kawanobe. K. Kogami, M. Matsui, Agric. Biol. Chem. 1986, 50, 1475; A. Saito, H. Matsushita, H. Kaneko, Chem. Lett. 1983, 729.

[34] a) Ae.deGroot, T. A.van Beek, Recl.Trav. Chim. Pays-Bas 1987, 106, 1; L. Garlaschelli.G. Vidari, Tetrahedron 1989, 45, 7371; L. Garlaschelli, G. Mellerio, G. Vidari, ibid. 1989, 45, 7379; J. D. White, L. P. J. Burton, J. Org. Chem. 1985, 50, 357; b) M. Fetizon, P. Goulaouic, 1. Hanna, T. Prange, ibid. 1988, 53, 5672.

[35] 5. V. Bhat, B. S. Bajwa, H. Dornauer, N. J. de Souza, Tetrahedron Lett. 1977, 1669; S. V. Bhat, B. S. Bajwa, H. Dornauer, J. Chem. Soc., Perkin Trans. 1 1982, 767

[36] K. B.Seamon, Ann. Reports Med.Chem. 1984,19, 293.

[37] A. K. Banerjee, H. H. Hurtado, M. C. Carrasco, Synth. Commun. 1980, 10, 261.

[38] Synthetic studies towards forskolin with direct construction of a $C(6)$-functionalized trinethyltrans-decalin: a) P. G. Baraldi, A. Barco, S. Benetti, G. P. Pollini, E. Polo, D. Simoni, $J$ Chem. Soc., Chen. Commun. 1986, 757; P. G. Baraldi, A. Barco, S. Benetti, V. Ferretti, G. P. Pollini, E. Polo, V. Zanirato, Tetrahedron 1989. 45,1517 ; b) E. J. Corey, P. Da Silva Jardine, Tetrahedron Lett. 1989, 30, 7297; see also [34b].

[39] E. J. Corey, P. Da Silva Jardine, J. C. Rohloff, J Am. Chem. Soc. 1988, $110,3672$.

[40] C. Fehr, J.Galindo, O. Guntern, Tetrahedron Lett. 1990, 3I, 4021.

[41] C. Fehr, J, Galindo, Swiss Patent application. No. $02283 / 900$, filed 9.7 .1990 . 